\title{
Astronomy development in Serbia in view of the IAU Strategic Plan
}

\author{
Olga Atanacković \\ Department of Astronomy, Faculty of Mathematics, University of Belgrade \\ email: olga@matf.bg.ac.rs
}

\begin{abstract}
An overview of astronomy development in Serbia in view of the goals envisaged by the IAU Strategic Plan is given. Due attention is paid to the recent reform of education at all levels. In the primary schools several extra topics in astronomy are introduced in the physics course. Attempts are made to reintroduce astronomy as a separate subject in the secondary schools. Special emphasis is put to the role and activities of the Petnica Science Center the biggest center for informal education in SE Europe, and to a successful participation of the Serbian team in International astronomy olympiads. Astronomy topics are taught at all five state universities in Serbia. At the University of Belgrade and Novi Sad students can enroll in astronomy from the first study year. The students have the training at the Ondrejov Observatory (Czech Republic) and at the astronomical station on the mountain Vidojevica in southern Serbia. Astronomy research in Serbia is performed at the Astronomical Observatory, Belgrade and the Department of Astronomy, Faculty of Mathematics, University of Belgrade. There are about 70 researchers in astronomy in Serbia (and about as many abroad) who participate in eight projects financed by the Ministry of Education and Science and in several international cooperations and projects: SREAC, VAMDC, Belissima (recruitment of experienced expatriate researchers), Astromundus (a 2-year joint master program with other four European universities), LSST. One of the goals in near future is twinning between universities in the SEE region and worldwide. The everincreasing activities of 20 amateur astronomical societies are also given.
\end{abstract}

